Textures and Microstructures, Vol. 34, pp. 43-54 Reprints available directly from the publisher Photocopying permitted by license only
(C) 2000 OPA (Overseas Publishers Association) N.V.

Published by license under the Gordon and Breach Science Publishers imprint. Printed in Malaysia.

\title{
EFFECT OF MICROSTRUCTURES ON DEFORMATION BEHAVIOUR OF ALUMINIUM MATRIX COMPOSITES IN LASER BENDING
}

\author{
K.C. CHAN* and J. LIANG \\ Department of Manufacturing Engineering, The Hong Kong Polytechnic \\ University, Yuk Choi Road, Hung Hom, Kowloon, Hong Kong
}

(Received 7 December 1999)

It is well known that the mechanical and deformation properties of metal matrix composites (MMCs) are related to their microstructures. However, less work has been carried out in laser bending to examine the dependency of microstructures of MMCs on deformation behaviour. In this paper, two aluminium-based metal matrix composites, Al2009/ $20 \mathrm{vol} \% \mathrm{SiC}_{\mathrm{w}}$ and $\mathrm{Al} 2009 / 20 \mathrm{vol} \% \mathrm{SiC}_{\mathrm{p}}$ were investigated. A YAG laser was used to scan the composites both parallel and perpendicular to their rolling directions. It was reported that under the same processing conditions, a larger bending angle was obtained for the $\mathrm{Al} 2009 / \mathrm{SiC}_{\mathrm{p}}$ composite. No significant change in microstructures was observed for both composites after bending. Experimental findings also revealed that for the particulate reinforced composite, a larger laser bending angle was obtained when the laser scanning direction was perpendicular to the rolling direction, whereas no significant difference was observed for the $\mathrm{Al} 2009 / \mathrm{SiC}_{\mathrm{w}}$ composite. These phenomena were shown to relate to the shape and distribution of reinforcements.

Keywords: Microstructures; Laser bending; Aluminium matrix composites; Anisotropic bending properties

\section{INTRODUCTION}

In the last decade, there have been a considerable amount of experimental and theoretical investigations on laser forming (Vollertsen, 1994a; Vollertsen et al., 1995; Yau et al., 1998). Relatively less work has

\footnotetext{
* Corresponding author.
} 
been reported on laser forming of hard and brittle materials, though it is considered to be a suitable process for these materials. Metal matrix composites (MMCs) are attractive for many structural applications because of their high specific strength, modulus of elasticity, thermal conductivity and structural stability (Hull and Clyne, 1996). However, they are relatively brittle and not easy to form at room temperature. There are commonly two types of commercially available discontinuous reinforced MMCs, i.e., whisker and particulate reinforced. Recently, the author and his workers have carried out preliminary investigations on the deformation behaviour of two aluminium-based MMC materials in laser bending. It has been reported that a large bending angle can be achieved for an $\mathrm{Al} 2009 / \mathrm{SiC}_{\mathrm{w}}$ composite and the bending angle is strongly related to the laser power, the processing velocity, and the number of irradiations. They have also examined the effect of sheet thickness, orientation and width on bending angle of an $\mathrm{Al} 6013 / \mathrm{SiC}_{\mathrm{p}}$ composite (Yau et al., 1996; Chan and Liang, 1999). The experimental results show that smaller bending angles are obtained when the laser scanning direction is parallel to the rolling direction. A linear relationship between bending angle and threshold line energy is obtained. It is, however, very worthwhile to further examine the effect of microstructures of MMCs in laser bending. In this paper, two aluminiumbased MMCs with different types of reinforcements are used for investigations.

\section{EXPERIMENTAL MATERIAL AND PROCEDURES}

Two commercially available aluminium-based MMCs, A12009 alloy reinforced with 20 vol\% $\mathrm{SiC}$ particles and the same matrix alloy with $20 \mathrm{vol} \% \mathrm{SiC}$ whiskers were used in this study. The materials supplied by Advanced Composite Corporation were manufactured by powder metallurgy. The nominal composition of the aluminium alloy is listed in Table I. Samples of thickness of $0.5 \mathrm{~mm}$ and dimensions of $10 \mathrm{~mm} \times 20 \mathrm{~mm}$ were prepared by wire electro-discharge machining. An $80 \mathrm{~W}$ YAG laser unit operating in continuous wave (CW) mode was used in the experiment to scan the specimens as shown in Fig. 1. In order to examine the effect of sheet orientation on the bending angle, the composites were scanned both parallel and perpendicular to their 
TABLE I Composition of the Al2009 alloy (wt\%)

\begin{tabular}{lcccccc}
\hline$C u$ & $M g$ & $Z n$ & $S i$ & $F e$ & $O$ & $A l$ \\
\hline $3.2-4.4$ & $1.0-1.6$ & 0.10 & 0.25 & 0.07 & 0.6 & Balance \\
\hline
\end{tabular}

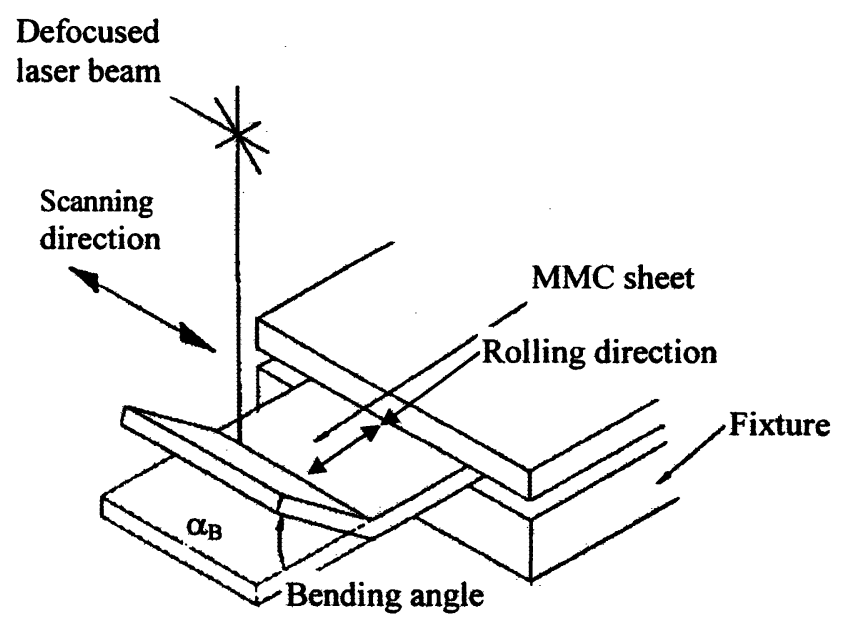

FIGURE 1 Schematic diagram of laser bending of MMC sheets.

rolling directions. No graphite coating was applied and a defocused laser beam with a diameter of $1.32 \mathrm{~mm}$ was used to avoid surface melting. A machine vision system including a high-resolution CCD camera, a specially designed fixture, a graphics interface board and a personal computer were equipped with the laser unit for angle measurements. The accuracy of the system is $\pm 0.5^{\circ}$. In order to examine the effect of microstructures on bending angle, the two composites were deformed under the same processing conditions.

A thermal mechanical analyzer was used to measure coefficient of thermal expansion (CTE) of the composites along the rolling and transverse directions. CTE measurements were performed between temperatures of $25^{\circ} \mathrm{C}$ and $350^{\circ} \mathrm{C}$ at a rate of $10^{\circ} \mathrm{C} \mathrm{min}^{-1}$. The crystallographic textures of the matrix alloy were measured by a Philips X-ray diffraction (XRD) system. Three incomplete pole figures: (111), (200) and (220) are obtained by the back reflection method at $5^{\circ}$ increments using $\mathrm{Cu} \mathrm{K} \alpha$ radiation. From the pole figures, the orientation 
distribution function (ODF) and the quantitative texture component were calculated by the software developed by Cai and Lee (1995) using the series expansion method. Tensile tests were carried out at room temperature to determine the mechanical properties of the composites. A scanning electron microscope (SEM) was used to examine the microstructures of the specimens at different locations, before and after laser bending.

\section{RESULTS AND DISCUSSIONS}

\section{Relationship Between Laser Bending Angle and the Number of Irradiations}

The relationship between laser bending angle and number of irradiations in two different scanning directions is shown in Fig. 2. A relatively linear relationship is observed, which is in agreement with that reported by Namba (1985), Scully (1987), Yau et al. (1996), Chan and Liang (1999). It is however inconsistent with the findings of Sprenger $e t$ al. (1994) which show a degressive course of bending angle. Yau et al. (1996) suggest that the influence of thickening in the edge and work

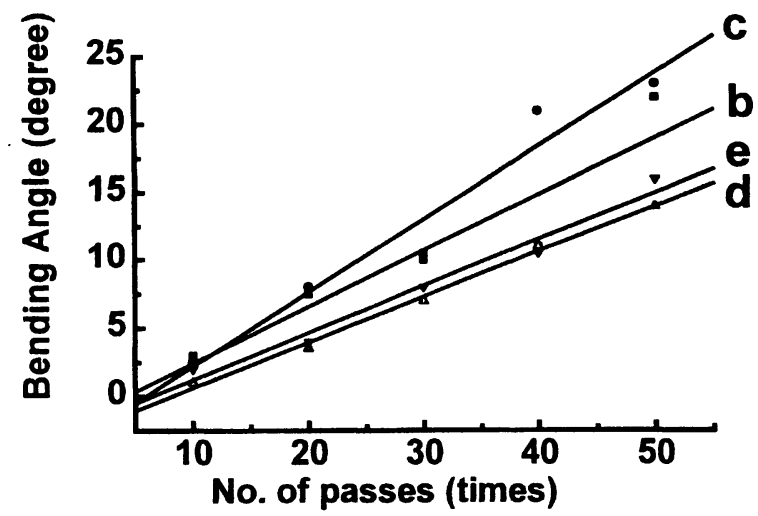

b-scanning direction parallel to the rolling direction (Al2009/SiCp) c-scanning direction perpendicular to the rolling direction (Al2009/SiCp) d-scanning direction parallel to the rolling direction $(\mathrm{Al} 2009 / \mathrm{SiCw})$ e-scanning direction perpendicular to the rolling direction (Al2009/SiCw)

FIGURE 2 Effect of sheet orientation on laser bending angle. 
hardening is the cause for non-linearity of the curve. Since this effect is not significant when the sheet thickness and the number of irradiations are small, a relatively linear relationship between bending angle and number of irradiations is obtained in the present paper. Experimental findings also reveal that for the $\mathrm{Al} 2009 / \mathrm{SiC}_{\mathrm{p}}$ composite, a larger laserbending angle is obtained when the scanning direction of laser beam is perpendicular to the rolling direction. But no significant difference is observed for the $\mathrm{Al} 2009 / \mathrm{SiC}_{\mathrm{w}}$ composite. Under the same processing conditions, the bending angle of the $\mathrm{Al} 2009 / \mathrm{SiC}_{\mathrm{p}}$ is shown to be larger than that of the $\mathrm{Al} 2009 / \mathrm{SiC}_{\mathrm{w}}$.

\section{Microstructural Examinations}

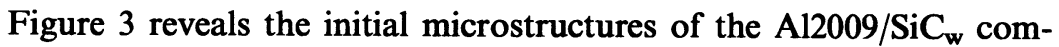
posite. A relatively random distribution of whiskers is observed. The dimensions of the whisker is $\sim 0.5 \mu \mathrm{m}$ in diameter and $10-80 \mu \mathrm{m}$ in length; whereas the distribution of particulates in $\mathrm{Al} 2009 / \mathrm{SiC}_{\mathrm{p}}$ is shown in Fig. 4, the particulates are not in ideal spherical shape and of an average size of $3 \mu \mathrm{m}$.

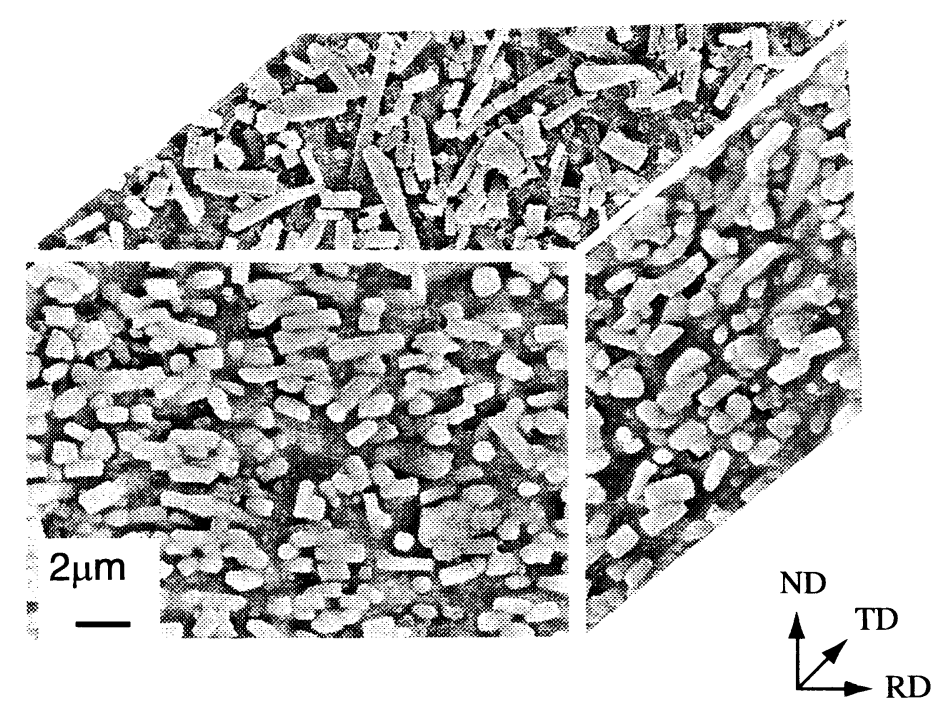

FIGURE 3 3-Dimensional view showing the distribution of $\mathrm{SiC}_{\mathrm{w}}$ in the $\mathrm{Al} 2009 / \mathrm{SiC}_{\mathrm{w}}$ composite. 


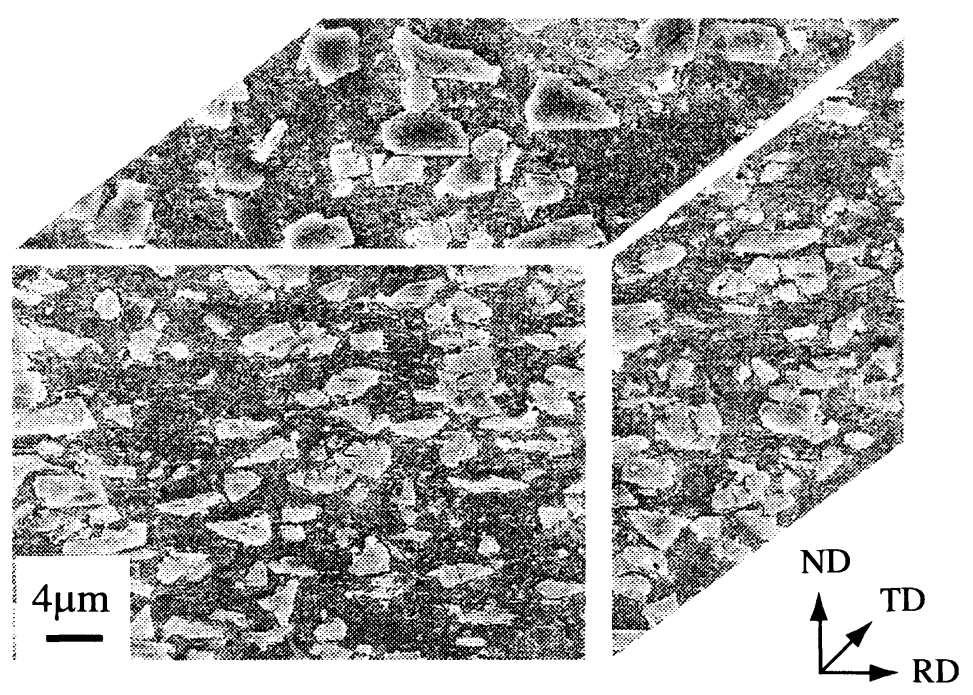

FIGURE 4 3-Dimensional view showing the distribution of $\mathrm{SiC}_{\mathrm{p}}$ in the $\mathrm{Al} 2009 / \mathrm{SiC}_{\mathrm{p}}$ composite.

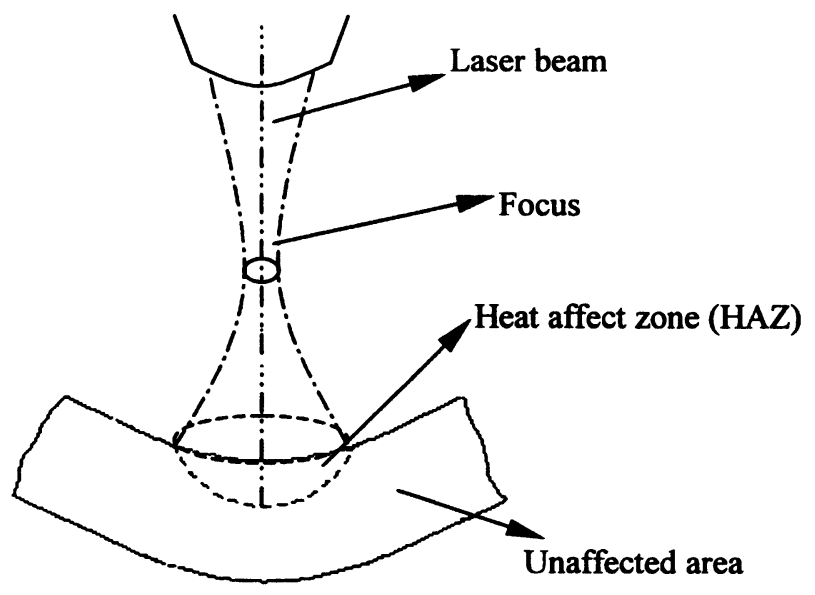

FIGURE 5 Schematic diagram of the heat affect zone after laser bending.

After laser bending, a clear heat affect zone (HAZ) is observed as shown in Fig. 5. Figure 6 shows the microstructures of the whiskerreinforced composite which was bent to $7^{\circ}$ after 30 irradiations, whereas, the microstructures of $\mathrm{Al} 2009 / \mathrm{SiC}_{\mathrm{p}}$ composite bent to $10^{\circ}$ 


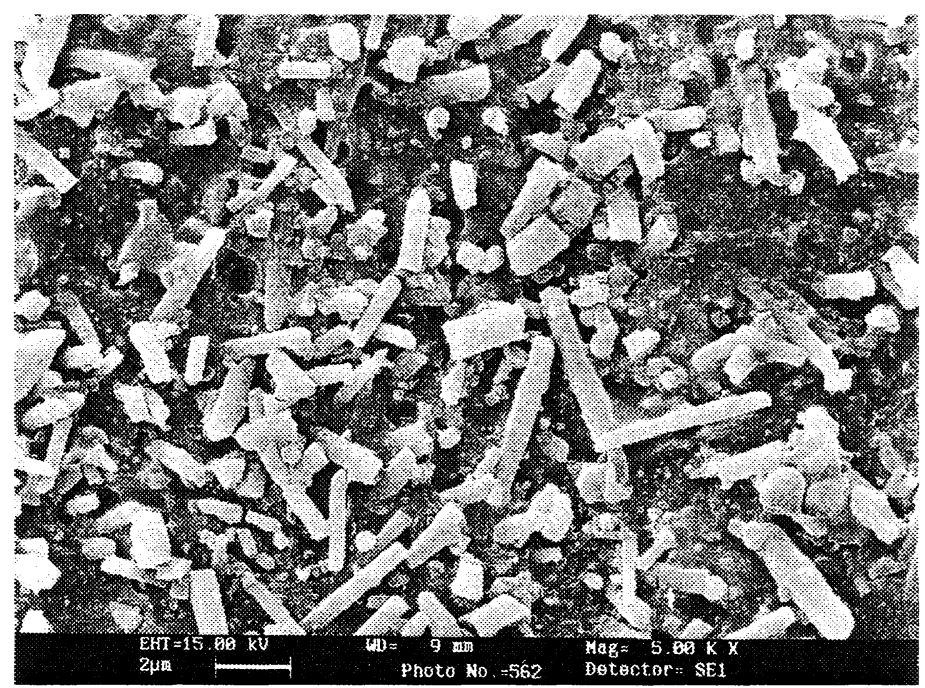

FIGURE 6 Microstructure of the laser $\mathrm{HAZ}$ of the $\mathrm{Al} 2009 / \mathrm{SiC}_{\mathrm{w}}$.

after 30 irradiations is shown in Fig. 7. No significant change in microstructures is found in these composites.

ODF of the $\mathrm{Al} 2009 / \mathrm{SiC}_{\mathrm{p}}$ and $\mathrm{Al} 2009 / \mathrm{SiC}_{\mathrm{w}}$ composites are shown in Figs. 8 and 9 respectively. It is shown that the matrix of both composites consists of random texture and some weak components. The results are in agreement with findings of Chen et al. (1998). It is considered that the matrix does not have any significant anisotropic properties and will not contribute to the overall anisotropic bending properties of $\mathrm{Al} 2009 / \mathrm{SiC}_{\mathrm{p}}$.

\section{Effect of Sheet Orientation and Reinforcement on Bending Angle}

Vollertsen (1994b) have proposed the following analytical equation to predict the angle $\left(\alpha_{B}\right)$ in laser bending

$$
\alpha_{\mathrm{B}}=3 \frac{\alpha_{\mathrm{th}} p_{1} A}{\rho C_{\mathrm{p}} v_{1} s_{0}^{2}}
$$

where $s_{0}$ is the sheet thickness, $v_{1}$ is the feed rate, $A$ is the absorption coefficient, $p_{1}$ is the heat input, $\alpha_{\text {th }}$ is the coefficient of thermal expansion, $\rho$ is the density, $C_{\mathrm{p}}$ is the heat capacity. This equation gives 


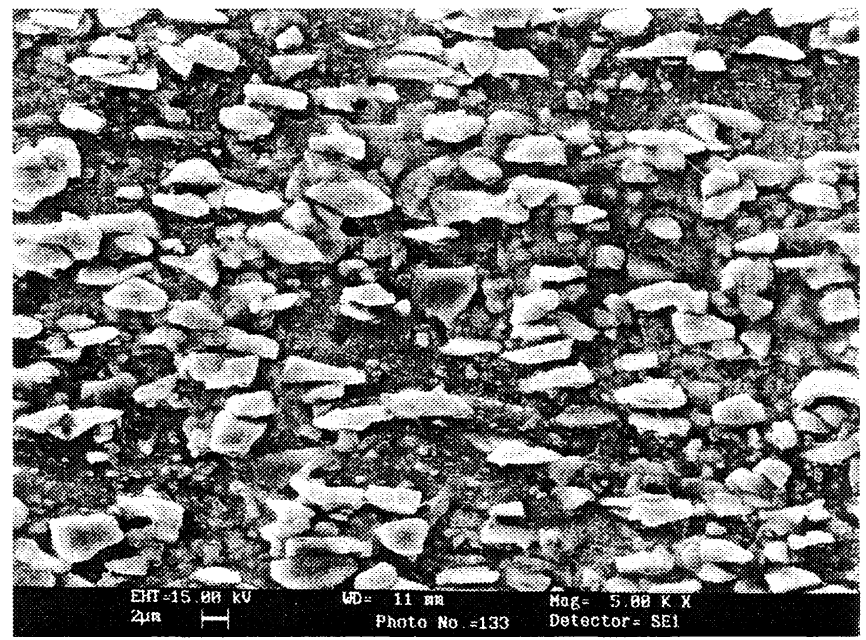

FIGURE 7 Microstructure of the laser $\mathrm{HAZ}$ of the $\mathrm{Al} 2009 / \mathrm{SiC}_{\mathrm{p}}$.

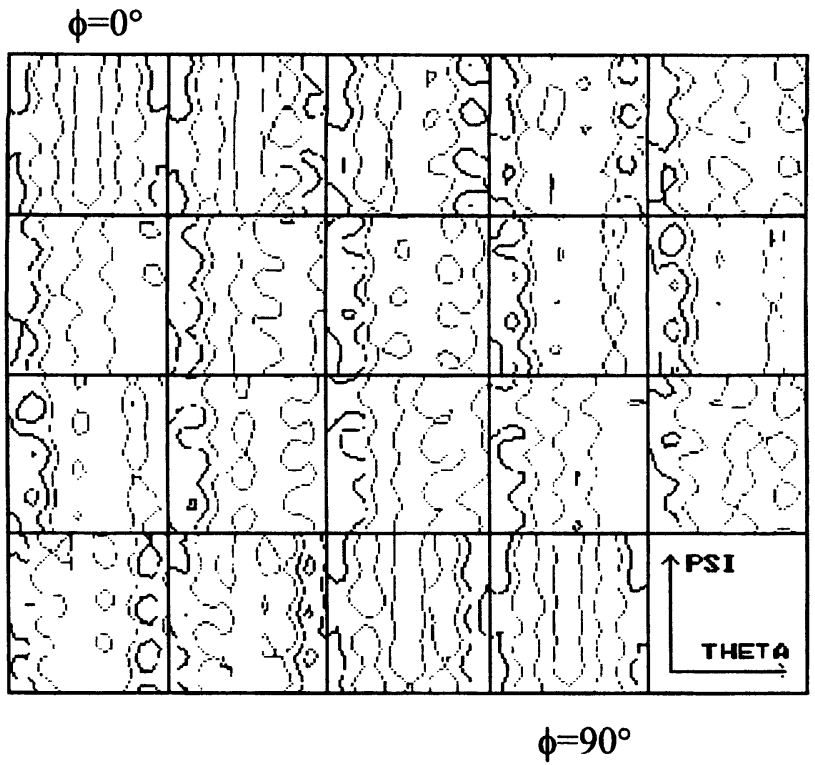

Levels: $1-2-3$

FIGURE $8 \phi$ sections $\left(\Delta \phi=5^{\circ}\right)$ of the ODF (of $\left.\mathrm{Al} 2009 / \mathrm{SiC}_{\mathrm{p}}\right)$. 


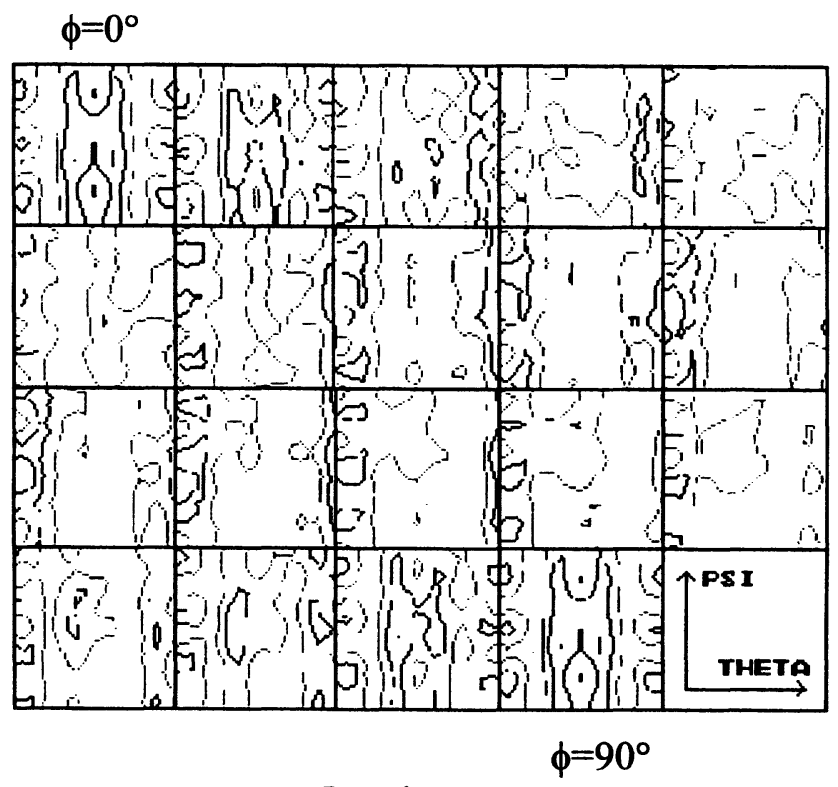

Level: $1-2-3$

FIGURE $9 \phi$ sections $\left(\Delta \phi=5^{\circ}\right)$ of the ODF (of $\mathrm{Al} 2009 / \mathrm{SiC}_{\mathrm{w}}$ ).

an analytical expression for the bend angle as a function of the energy (laser power, absorption, path feed rate), geometric (sheet thickness) and material parameters (coefficient of thermal expansion, density, heat capacity). Other researchers have further reported that the mechanical properties of materials are also an important material parameter affecting bending angle (Yau et al., 1997). It is found that materials with greater yield strength result in smaller bending angle. The mechanical properties of composites are known to relate to the types and distribution of reinforcements, and the microstructures of the matrix alloy. For both $\mathrm{Al} 2009 / \mathrm{SiC}_{\mathrm{p}}$ and $\mathrm{Al} 2009 / \mathrm{SiC}_{\mathrm{w}}$, a weak crystallographic texture as shown in Figs. 8 and 9 is obtained in the matrix, which suggests that the matrix has relatively isotropic properties. Tensile tests were conducted at room temperature to reveal the overall mechanical properties of the composites. The results show that the yield strength of the whisker reinforced composite is $208.8 \mathrm{MPa}$, which is significantly larger than that of the particulate reinforced one $(121.2 \mathrm{MPa})$. This is in 
agreement with the findings that a smaller bending angle is obtained for $\mathrm{Al} 2009 / \mathrm{SiC}_{\mathrm{w}}$ than $\mathrm{Al} 2009 / \mathrm{SiC}_{\mathrm{p}}$. No significant difference in tensile strength is observed for different sheet orientations of the $\mathrm{Al} 2009 / \mathrm{SiC}_{\mathrm{w}}$ composite, as the distribution of the whiskers is quite random. This is also in agreement with the findings that similar bending behaviour is obtained for two different scanning directions of $\mathrm{Al} 2009 / \mathrm{SiC}_{\mathrm{w}}$ as shown in Fig. 2. It is interesting to note that for the $\mathrm{Al} 2009 / \mathrm{SiC}_{\mathrm{p}}$ composite, the yield strength of the composite in the rolling direction is slightly larger than that at transverse direction, which cannot explain the phenomenon that the bending angle obtained when the laser scanning direction is perpendicular to the rolling direction is lager than that parallel to it as shown in Fig. 2.

Typical SEM micrograph as shown in Fig. 4 indicates that silicon carbide particulates are not distributed homogeneously and have an aspect ratio of 2, which are considered to affect the CTE and mechanical properties of the composite. The schematic diagram of the distribution of the particles is shown in Fig. 10. It is noted that the coefficient of thermal expansion of the matrix is nearly four times greater than that of the reinforcements (Liu et al., 1993; Charles, 1989). It is considered that particulates with the major axis parallel to the rolling direction led to higher CTE in the rolling direction. The results of CTE measurement shown in Fig. 11 indicate that CTE in the rolling direction is significantly higher than that at the transverse direction. As shown in Eq. (1), a large CTE value results in a large bending angle. This is in consistence to the findings that a larger laser bending angle is obtained when the laser scanning direction is perpendicular to the rolling direction.

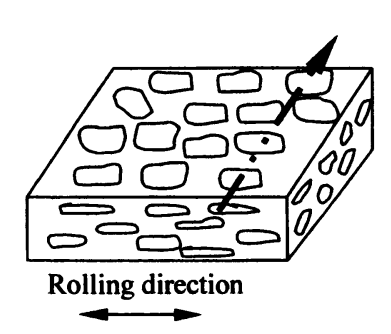

High thermal expansion

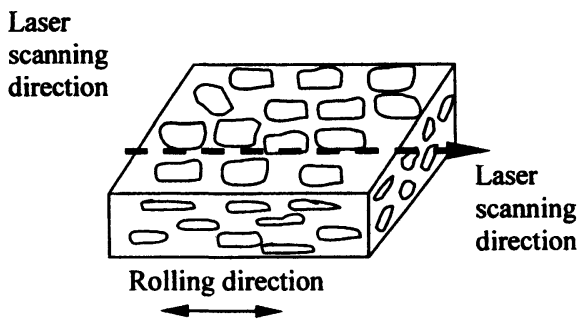

High thermal expansion

FIGURE 10 Schematic diagram of distribution of particulates of $\mathrm{Al} 2009 / \mathrm{SiC}_{\mathrm{p}}$. 


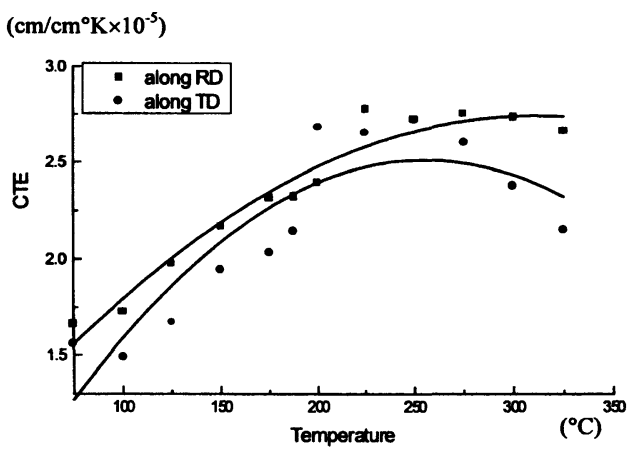

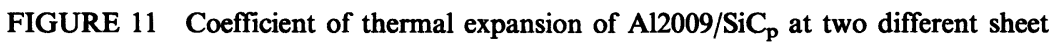
orientations.

\section{CONCLUSIONS}

In this paper, the deformation behaviour of two MMCs in laser bending, $\mathrm{Al} 2009 / 20$ vol\% $\mathrm{SiC}_{\mathrm{p}}$ and $\mathrm{Al} 2009 / 20$ vol\% $\mathrm{SiC}_{\mathrm{w}}$ were examined and compared. Under the same processing conditions, a larger bending angle was obtained for the $\mathrm{Al} 2009 / \mathrm{SiC}_{\mathrm{p}}$ composite. No significant change in microstructures was observed for both composites after bending. A larger laser bending angle was obtained when the laser scanning direction was perpendicular to the rolling direction for the $\mathrm{Al} 2009 / \mathrm{SiC}_{\mathrm{p}}$, whereas relatively isotropic bending behaviour was observed for the $\mathrm{Al} 2009 / \mathrm{SiC}_{\mathrm{w}}$ composite. The anisotropic properties of the $\mathrm{Al} 2009 / \mathrm{SiC}_{\mathrm{p}}$ composite are shown to strongly relate to the distribution and shape of $\mathrm{SiC}_{\mathrm{p}}$ reinforcements, which result in a significant variation in CTE in different sheet orientations.

\section{Acknowledgements}

The authors wish to express their gratitude for the financial support of the project from the Hong Kong Research Grant Council under the code No. Q185 and the support from the Hong Kong Polytechnic University.

\section{References}

Cai, M.J. and Lee, W.B. (1995). The development of a computer software system for the prediction of formability parameters of sheet metals from X-ray diffraction data, Journal of Materials Processing Technology, 48, 51-57. 
Chan, K.C. and Liang, J. (1999). Laser bending of an $\mathrm{Al} 6013 / \mathrm{SiC}_{\mathrm{p}}$ aluminium matrix composite sheet. Journal of Materials Processing Technology (in print).

Charles, Lynch T. Ed. (1989). Practical Handbook of Materials Science, CRC Press Inc.

Chen, L.Q., Lu, Y.X., Lee, C.S., Bi, J. and Li, R.K.Y. (1998). Mechanical properties and texture of particulate-reinforced aluminium alloy matrix composite under hot- and cold-rolling conditions. Texture and Microstructures, 31(1-2), 43-52.

Hull, D. and Clyne, T.W. (1996). An Introduction to Composite Materials, Cambridge University Press.

Liu, C., Michal, G. and Lewandowski, J.J. (1993). Residual stresses in Al based SiC particulate composite, Residual Stresses in Composites, TMS.

Namba, Y. (1985). Laser forming in space, Proceedings of International Conference on Laser, pp. 403-407.

Scully, K. (1987). Laser Line Heating, Journal of Ship Production, 3(4), 237-246.

Sprenger, A., Vollertsen, F., Steen, W.M. and Watkin, K. (1994). Influence of strain hardening on laser bending, Laser Assistant Net Shape Engineering, Proceeding of the LANE'94, pp. 345-360.

Vollertsen, F. (1994a). An analytical model for laser bending, Lasers in Engineering, 2, 261-276.

Vollertsen, F. (1994b). Mechanisms and models for laser forming. Laser Assistant Net Shape Engineering, Proceeding of the LANE'94, pp. 345-359.

Vollertsen, F., Komel, I. and Kalst, R. (1995). The laser bending of steel foils for microparts by the buckling mechanism - A model, Mater. Sci. Eng., 3, 107-119.

Yau, C.L., Chan, K.C. and Lee, W.B. (1996). Laser bending of Al-based metal matrix composites sheets, Proceedings of the 15th Int. Congress on Applications of Lasers and Electro-optics, Detroit, USA.

Yau, C.L., Chan, K.C. and Lee, W.B. (1997). Laser Assistant Net Shape Engineering 2, Proceeding of the LANE'97, pp. 357-365.

Yau, C.L., Chan, K.C. and Lee, W.B. (1998). Laser bending of leadframe materials. Journal of Materials Processing Technology, 82, 117-121. 